\section{Growth Analysis and Photosynthesis Measurements of Cucumber Seedlings Grown under Light with Different Red to Far-red Ratios}

\author{
Toshio Shibuya ${ }^{1}$, Ryosuke Endo, and Yoshiaki Kitaya \\ Graduate School of Life and Environmental Sciences, Osaka Prefecture \\ University, Gakuen-cho, Naka-ku, Sakai, Osaka 599-8531, Japan
}

\author{
Saki Hayashi \\ School of Life and Environmental Sciences, Osaka Prefecture University, \\ Gakuen-cho, Naka-ku, Sakai, Osaka 599-8531, Japan
}

Additional index words. biomass allocation, leaf enlargement, net assimilation, photoselective film, relative growth rate

\begin{abstract}
Light with a higher red to far-red ratio (R:FR) than sunlight reduces plant growth, but the cause has not been firmly established. In the present study, cucumber seedlings were grown under normal light (similar to sunlight; $R: F R=1.4$ ) from metalhalide lamps or high-R:FR light $(\mathrm{R}: F R=4.3)$ created by transmitting their light through FR-absorbing film, and then their growth parameters and photosynthesis were compared. The relative growth rate (RGR) at high R:FR was $92 \%$ of that under normal R:FR, although the net assimilation rate (NAR) did not differ between the treatments, indicating that changes in net photosynthesis per unit leaf area did not cause the growth inhibition at high R:FR. The $\mathrm{CO}_{2}$ exchange per unit leaf area did not differ between the treatments, which supports this hypothesis. The leaf area ratio (LAR) of total plant dry weight of high R:FR seedlings to that of normal R:FR seedlings was also $92 \%$. This suggests that growth suppression in the high R:FR seedlings was caused mainly by decreased LAR. The specific leaf area (SLA) and leaf weight ratio (LWR), components of LAR, under high-R:FR light were $89 \%$ and $105 \%$, respectively, of those under normal light, indicating that the smaller LAR at high R:FR mainly results from suppressed leaf enlargement per unit leaf dry matter.
\end{abstract}

Photo-selective films that absorb FR light (FR-absorbing films) have been used to control the growth and development of horticultural crops (Demotes-Mainard et al., 2016; Rajapakse and Shahak, 2007; Rajapakse et al., 1999). Under these films, shoot length, which is an important criterion for the quality of transplants and pot plants, can be shortened without using chemical growth regulators (Cerny et al., 2003; Li et al., 2000; Runkle and Heins, 2002; Wilson and Rajapakse, 2001), thereby improving tolerance to mechanical stress including wind damage (Latimer and Mitchell, 1988). The reduction of shoot elongation is due to the $\mathrm{R}: \mathrm{FR}$ of the filtered light, which is higher than that of sunlight due to the film's selective

Received for publication 1 Apr. 2016. Accepted for publication 27 Apr. 2016.

This research was supported by a Japan Society for the Promotion of Science Grant-in-Aid for Scientific Research (B) (KAKENHI 24380140, KAKENHI 15H04575), and by a joint research agreement between Osaka Prefecture University and Yanmar Co., Ltd. The authors thank Ryo Matsuda (University of Tokyo) and Keach Murakami (University of Tokyo) for valuable discussion.

${ }^{1}$ Corresponding author. E-mail: shibuya@envi. osakafu-u.ac.jp. absorption of FR light. This light (hereafter, "high-R:FR light") increases the proportion of active phytochrome and thereby suppresses shoot elongation (Franklin, 2008; Sasidharan et al., 2008; Smith and Whitelam, 1997). In addition to reducing extension growth, the FR-absorbing films also decrease plant dry matter production (Cerny et al., 2003; Fletcher et al., 2005; Li et al., 2000). Several studies have demonstrated that highR:FR light decreases plant dry matter production even at equivalent photosynthetic photon fluxes (PPFs) (Hogewoning et al., 2010; Li and Kubota, 2009; Shibuya et al., 2010a), but the exact cause of this decrease has not been firmly established.

The purpose of the present study was to determine the factor or factors that limit plant growth under high-R:FR light by analyzing its effects on the components that contribute to plant growth (Hunt et al., 2002; Radford, 1967). In these methods, the RGR is calculated by multiplying the LAR by the NAR, which are correlated with the light interception area per plant and the net photosynthetic rate per unit leaf area, respectively. The highR:FR light has been shown to alter these growth parameters. There have been many reports that leaf enlargement (correlated with LAR) was inhibited under high-R:FR light (Fletcher et al., 2005; Heraut-Bron et al.,
1999; Hogewoning et al., 2010; Li and Kubota, 2009; Shibuya et al., 2010a). The suppressed leaf enlargement decreases the light-interception area, and this could explain the reduction in dry matter production under high-R:FR light (Fletcher et al., 2005; Li and Kubota, 2009). If so, a smaller LAR can result from decreased leaf enlargement per unit leaf dry matter, decreased allocation of dry matter to the leaves vs. stems resulted from the acceleration of stem elongation, or both (Casal et al., 1987). However, leaf enlargement has not been investigated sufficiently well for plants grown under high R:FR lights to determine which explanation is correct.

Contradictory results have been reported for NAR. Heraut-Bron et al. (1999) demonstrated that the R:FR did not affect photosynthesis per unit leaf area of white clover (Trifolium repens L.). However, other reports demonstrated that low-R:FR light reduces the photosynthetic performance per unit leaf area of common bean (Phaseolus vulgaris L.), cucumber (Cucumis sativus L.), and other several species of different growth habit (Barreiro et al., 1992; Hogewoning et al., 2010; Pons and de Jong-Van Berkel, 2004; Shibuya et al., 2010a, 2012, 2015), although Yang et al. (2013) reported the opposite results for chrysanthemum (Chrysanthemum $\times$ grandiflorum Tzvelv). In these reports, photosynthesis of a single leaf was measured under leaf chamber conditions, and thus the results may be different from results of whole-plant photosynthesis under growing conditions, which are more appropriate to explain RGRs.

In the present study, cucumber seedlings were grown under light with a normal R:FR (similar to that of sunlight) or under highR:FR light created by FR-absorbing film, and their growth parameters were determined by the growth analysis methods. In addition, net and gross photosynthesis per unit leaf area and of the whole plant were evaluated during the growing period to follow the change in photosynthetic performance and validate the results of the growth analysis.

\section{Materials and Methods}

Growth conditions. Cucumber cv. Hokushin seeds were sown in plastic pots $(60 \mathrm{~mm}$ in diameter, $55 \mathrm{~mm}$ in height; 1 plant per pot) containing vermiculite. The plants were then grown in a growth chamber. Metal-halide lamps (DR400/TL; Toshiba Lighting \& Technology Corp., Yokosuka, Japan) were used with a spectrum similar to that of sunlight (R:FR = 1.4) for illumination. FR-absorbing film (prototype, NIRF-L-PP-10; Yanmar Co., Ltd., Osaka, Japan, and Panac Advance Co., Ltd., Tokyo, Japan) were placed between the lights and half of the seedlings. The R:FR under the FR-absorbing film was 4.3 . The R:FR was defined as the ratio of photon flux between 600 and $700 \mathrm{~nm}(\mathrm{R})$ to that between 700 and $800 \mathrm{~nm}$ (FR). The film transmits $\approx 40 \%$ of $P P F$. For the other half of the seedlings, 
a shade net (4S.SU45, Sekisui Nano Coat Technology Co., Ltd., Gamagori, Japan) that does not change the R:FR were placed between the lights and the plants to reduce the $P P F$ by the same amount. Figure 1 shows the resulting spectra in the two treatments. The $P P F$ at the leaf surface was maintained at $300 \mu \mathrm{mol} \cdot \mathrm{m}^{-2} \cdot \mathrm{s}^{-1}$ during plant growth by adjusting the distance between the lamps and the canopy surface daily. The light:dark period was $16: 8 \mathrm{~h}$ throughout the growing period. The air temperature and relative humidity were maintained at $27{ }^{\circ} \mathrm{C}$ and $50 \%$, respectively. The pots were immersed to a depth of 5 to $10 \mathrm{~mm}$ in nutrient solution (the A-type recipe of OAT Solution; OAT Agrio Co. Ltd., Tokyo, Japan). The seedlings were arranged with sufficient space to avoid mutual shading among neighboring seedlings.

Growth analysis. Six seedlings in each treatment group were sampled at 6 and $13 \mathrm{~d}$ after seeding. On day 13 , the cotyledons and first true leaf had expanded, but the second true leaf had not expanded. The self-shading among the leaves were not observed during the experimental period. The leaf area and shoot length were measured, and then the whole-plant and leaf dry weight (DW, measured after $3 \mathrm{~d}$ of drying at $80^{\circ} \mathrm{C}$ ) were determined. The leaf area was measured with an image scanner and "LIA for Win32" image analysis software (K. Yamamoto, Nagoya University, Nagoya, Japan, http://www.agr.nagoya-u.ac. $\mathrm{jp} / \sim$ shinkan/LIA32/index.html). The leaf mass per unit area (LMA) were calculated by dividing leaf DW by leaf area $13 \mathrm{~d}$ after seeding. Three seedlings for each treatment group were also sampled 7, 9, and $11 \mathrm{~d}$ after seeding to measure the whole-plant DW. The RGR $\left(\mathrm{d}^{-1}\right)$, relative leaf expansion rate (RLER, $\left.\mathrm{d}^{-1}\right)$, NAR $\left(\mathrm{g} \cdot \mathrm{m}^{-2} \cdot \mathrm{d}^{-1}\right.$ DW basis), LAR $\left(\mathrm{m}^{2} \cdot \mathrm{g}^{-1}\right)$, SLA $\left(\mathrm{m}^{2} \cdot \mathrm{g}^{-1}\right)$, and LWR (dimensionless) were calculated using the following

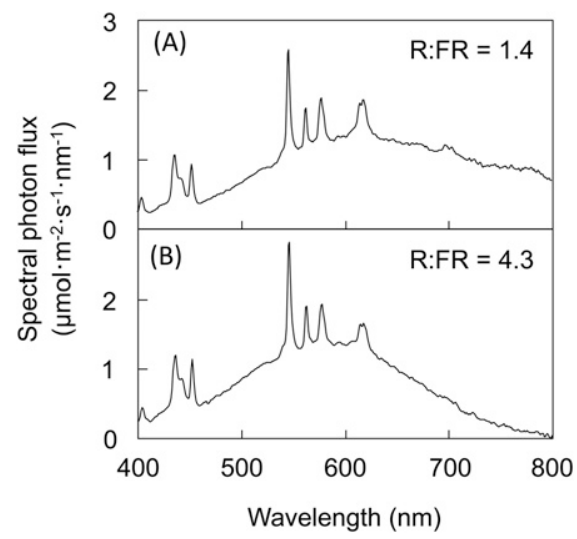

Fig. 1. Spectra of (A) light from metal-halide lamps (MHLs) transmitted through a shade net that did not change the light quality, and (B) light from MHLs transmitted through the far-redlight-absorbing film. The red to far-red ratio (R: FR) was defined as the ratio of photon flux between 600 and $700 \mathrm{~nm}(\mathrm{R})$ to that between 700 and $800 \mathrm{~nm}$ (FR). equations (Granier and Tardieu, 1998; Hunt et al., 2002; Radford, 1967):

$$
\begin{aligned}
\mathrm{RGR}= & \frac{\ln W_{2}-\ln W_{1}}{t_{2}-t_{1}}=\mathrm{NAR} \times \mathrm{LAR} \\
\mathrm{RLER}= & \frac{\ln A_{2}-\ln A_{1}}{t_{2}-t_{1}} \\
\mathrm{NAR}= & \frac{1}{t_{2}-t_{1}} \times \int_{t_{1}}^{t_{2}} \frac{1}{A} \times \frac{\mathrm{d} W}{\mathrm{~d} t} \mathrm{~d} t \\
= & \frac{W_{2}-W_{1}}{A_{2}-A_{1}} \times \frac{\ln A_{2}-\ln A_{1}}{t_{2}-t_{1}} \\
\mathrm{LAR}= & \frac{1}{t_{2}-t_{1}} \times \int_{t_{1}}^{t_{2}} \frac{A}{W} \mathrm{~d} t=\frac{A_{2}-A_{1}}{\ln A_{2}-\ln A_{1}} \\
& \times \frac{\ln W_{2}-\ln W_{1}}{W_{2}-W_{1}}=\mathrm{SLA} \times \mathrm{LWR}
\end{aligned}
$$

$$
\begin{aligned}
\text { SLA }= & \frac{1}{t_{2}-t_{1}} \times \int_{t_{1}}^{t_{2}} \frac{A}{L} \mathrm{~d} t=\frac{A_{2}-A_{1}}{\ln A_{2}-\ln A_{1}} \\
& \times \frac{\ln L_{2}-\ln L_{1}}{L_{2}-L_{1}} \\
\mathrm{LWR}= & \frac{1}{t_{2}-t_{1}} \times \int_{t_{1}}^{t_{2}} \frac{L}{W} \mathrm{~d} t=\frac{L_{2}-L_{1}}{\ln L_{2}-\ln L_{1}} \\
& \times \frac{\ln W_{2}-\ln W_{1}}{W_{2}-W_{1}}
\end{aligned}
$$

where $W_{1}$ and $W_{2}$ are the total DW (g/plant) at times $t_{1}$ and $t_{2}$ (6 and $13 \mathrm{~d}$ after seeding, respectively), $A_{1}$ and $A_{2}$ are the corresponding total leaf areas $\left(\mathrm{m}^{2} / \mathrm{plant}\right)$, and $L_{1}$ and $L_{2}$ are the corresponding leaf DW values (g/plant).

Photosynthesis measurements. Seedling photosynthesis was measured once per day from 6 to $13 \mathrm{~d}$ after seeding using a $\mathrm{CO}_{2}$ assimilation chamber $(\mathrm{L} \times \mathrm{D} \times \mathrm{H}: 200 \times 200 \times$ $150 \mathrm{~mm}$ ) with continuous air flow. The $\mathrm{CO}_{2}$ exchange rates were determined $\approx 2-7 \mathrm{~h}$ after the start of the photoperiod. The measure-

\begin{tabular}{|c|c|c|c|c|c|c|c|}
\hline \multirow[b]{2}{*}{ Treatment } & \multicolumn{4}{|c|}{ DW (mg/plant) } & \multirow[b]{2}{*}{$\begin{array}{l}\text { Leaf area } \\
\left(\mathrm{cm}^{2} / \text { plant }\right)\end{array}$} & \multirow[b]{2}{*}{$\begin{array}{l}\text { LMA } \\
\left(\mathrm{m}^{2} \cdot \mathrm{g}^{-1}\right)\end{array}$} & \multirow[b]{2}{*}{$\begin{array}{c}\text { Shoot } \\
\text { length }(\mathrm{mm})\end{array}$} \\
\hline & Leaf & $\begin{array}{l}\text { Hypocotyl } \\
\text { and petiole }\end{array}$ & Root & Total & & & \\
\hline High R:FR & $254 \pm 6$ & $37 \pm 1$ & $52 \pm 2$ & $343 \pm 7$ & $167 \pm 6$ & $16.1 \pm 0.2$ & $26.7 \pm 1.0$ \\
\hline ormal R:FR & $300 \pm 7$ & $60 \pm 3$ & $62 \pm 3$ & $421 \pm 12$ & $232 \pm 5$ & $14.2 \pm 0.2$ & $37.5 \pm 1.8$ \\
\hline$P$ value & $<0.001$ & $<0.001$ & 0.019 & $<0.001$ & $<0.001$ & $<0.001$ & $<0.001$ \\
\hline
\end{tabular}
ments were conducted with three replicate groups for each treatment $(n=3)$. The number of seedlings per group ranged from two to six, which was determined based on seedling size (i.e., fewer seedlings were used as the plants grew larger to avoid mutual shading during the

Table 1. The dry weights (DWs), leaf area, leaf mass per unit area (LMA), and shoot length of cucumber seedlings grown under light with a high red to far-red ratio $(\mathrm{R}: \mathrm{FR}=4.3)$ or natural $\mathrm{R}: \mathrm{FR}(1.4), 13 \mathrm{~d}$ after seeding.

Data are the average \pm SE for six plants $(\mathrm{n}=6)$. measurements). An air pump was used to pass air through the chamber (at 4-6 L. $\mathrm{min}^{-1}$ ). The $\mathrm{CO}_{2}$ concentration at the inlet and outlet of the assimilation chamber was sampled alternately at 1-min intervals using another air pump with a flow rate of $1.0 \mathrm{~L} \cdot \mathrm{min}^{-1}$. The $\mathrm{CO}_{2}$ concentration in the air samples was measured with an LI-7000 IR gas analyzer (LI-COR Inc., Lincoln, NE). The whole-plant $\mathrm{CO}_{2}$ exchange rate $\left(\mathrm{mol} \cdot \mathrm{m}^{-2} \cdot \mathrm{s}^{-1}\right.$ per plant) was calculated by multiplying the air flow rate $\left(\mathrm{m}^{3} \cdot \mathrm{s}^{-1}\right)$ by the difference in $\mathrm{CO}_{2}$ concentration between the inlet and outlet of the assimilation chamber $\left(\mathrm{mol} \cdot \mathrm{m}^{-3}\right)$ and then dividing this difference by the number of plants. The $\mathrm{CO}_{2}$ concentrations were averaged over 10 samples (i.e., over a 20-min period). The $\mathrm{CO}_{2}$ exchange rate was also measured in the dark, with darkness created by temporarily covering the chamber with shadecloth. The $\mathrm{CO}_{2}$ concentration and relative humidity in the assimilation chamber were stable during the measurement.

The $\mathrm{CO}_{2}$ exchange rates under light and dark conditions represented the whole-plant net photosynthetic rate $\left(\mathrm{P}_{\mathrm{N}}\right)$ and the dark respiration rate $\left(R_{D}\right)$, respectively. $R_{D}$ did not differ significantly between the two light treatments, so we have not presented or discussed that data. The gross photosynthetic rate $\left(\mathrm{P}_{\mathrm{G}}\right)$ was determined by subtracting $\mathrm{R}_{\mathrm{D}}$ from $\mathrm{P}_{\mathrm{N}}$ to compare the photosynthetic performance between the treatments. To determine the $\mathrm{P}_{\mathrm{N}}$, $\mathrm{R}_{\mathrm{D}}$, and $\mathrm{P}_{\mathrm{G}}$ per unit leaf area, the leaf areas of the seedlings used for the $\mathrm{CO}_{2}$ exchange measurement were estimated from the leaf length and width by using a linear relationship between leaf area and length $\times$ width that had been determined in a preliminary experiment.

The NAR $\left(\mathrm{g} \cdot \mathrm{m}^{-2} \cdot \mathrm{s}^{-1}\right.$, DW basis) was also calculated from the $\mathrm{CO}_{2}$ exchange rates (for comparison with the NAR calculated based on the growth analysis) using the following equation:

$$
\begin{aligned}
\mathrm{NAR}= & \sum_{t=6}^{13}\left(P_{\mathrm{N} t} \times \mathrm{PP}+R_{\mathrm{D} t} \times \mathrm{DP}\right) \\
& \times 44 \times \frac{1}{1.63} \times \frac{1}{8}
\end{aligned}
$$

where $P_{\mathrm{N} t}$ and $R_{\mathrm{D} t}$ are the net photosynthetic rate and dark respiration rate per unit leaf area $\left(\mathrm{mol} \cdot \mathrm{m}^{-2} \cdot \mathrm{s}^{-1}, \mathrm{CO}_{2}\right.$ basis) at $t$ days after seeding, $\mathrm{PP}$ and DP are the photoperiod $(16 \mathrm{~h}=57,600 \mathrm{~s})$ and dark period ( $8 \mathrm{~h}=28,800 \mathrm{~s})$, respectively, and $44,1.63$, and 8 are the molar weight of $\mathrm{CO}_{2}\left(\mathrm{~g} \cdot \mathrm{mol}^{-1}\right)$, the $\mathrm{CO}_{2}$ assimilation per unit DW $\left[\mathrm{CO}_{2} / \mathrm{DW}(\mathrm{g} / \mathrm{g})\right]$, and measuring period (d), respectively.

Statistical analysis. Significant differences between treatment means were identified using 
Student's $t$ test. The interaction effects of the determination method (growth vs. photosynthetic analysis) and the treatment on values of NAR were determined by two-way analysis of variance. The statistical analyses were performed using the Statcel 2 software (OMS Publishing Inc., Tokorozawa, Japan).

\section{Results and Discussion}

The total DW and leaf area of the high-R: FR seedlings were $81 \%$ and $72 \%$, respectively, of those of the seedlings grown under normal light $13 \mathrm{~d}$ after seeding (Table 1). These results confirmed the general finding that growth and leaf expansion are suppressed under high-R:FR light. The LMA and shoot length of the high-R:FR seedlings were greater $(113 \%)$ and shorter $(71 \%)$, respectively, than those of the normal R:FR seedlings. These morphological traits of the high-R:FR seedlings agree with previous reports (Hogewoning et al., 2010; Shibuya et al.,

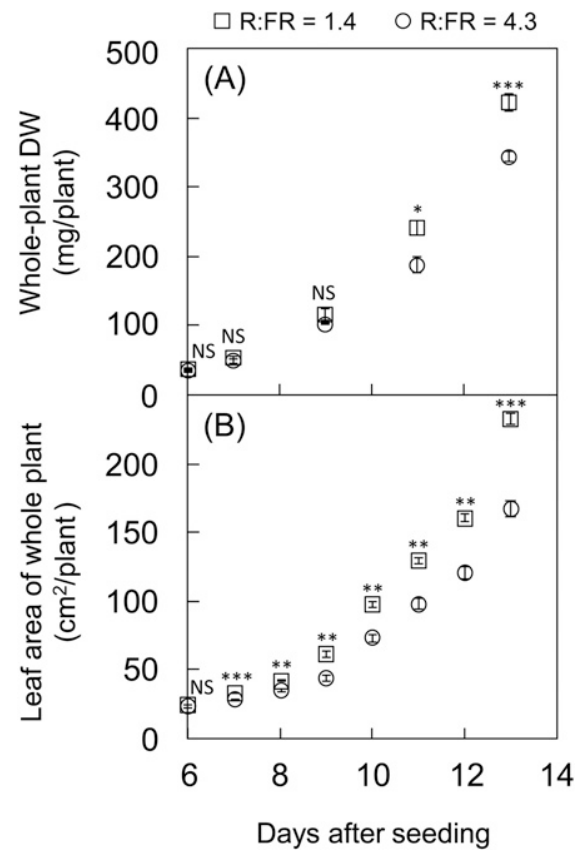

Fig. 2. Time courses of whole-plant dry weight (DW) and leaf area in cucumber seedlings under light with a high red to far-red ratio ( $\mathrm{R}$ : $\mathrm{FR}=4.3$ ) or natural R:FR (1.4). Data are the average \pm SE (DW, days 6 and 13, $\mathrm{n}=6$; DW, day 7 to $12, n=3$; leaf area, $n=6$ ). Leaf areas from day 7 to 12 were estimated from the leaf length and width. NS, no significant difference between treatments; $* P<0.05 ; * * P<0.01$; $* * * P<0.001$ ( $t$ test $)$.

Table 2. The relative growth rate (RGR), relative leaf expansion rate (RLER), net assimilation rate (NAR, dry weight basis), leaf area ratio (LAR), specific leaf area (SLA), and leaf weight ratio (LWR) of cucumber seedlings grown under light with a high red to far-red ratio (R:FR=4.3) or natural R:FR (1.4) during the experimental period.

\begin{tabular}{lcccccc}
\hline Treatment & $\begin{array}{c}\text { RGR } \\
\left(\mathrm{d}^{-1}\right)\end{array}$ & $\begin{array}{c}\text { RLER } \\
\left(\mathrm{d}^{-1}\right)\end{array}$ & $\begin{array}{c}\text { NAR } \\
\left(\mathrm{g} \cdot \mathrm{m}^{-2} \cdot \mathrm{d}^{-1}\right)\end{array}$ & $\begin{array}{c}\text { LAR } \\
\left(\mathrm{m}^{2} \cdot \mathrm{g}^{-1}\right)\end{array}$ & $\begin{array}{c}\text { SLA } \\
\left(\mathrm{m}^{2} \cdot \mathrm{g}^{-1}\right)\end{array}$ & LWR \\
\hline High R:FR & $0.324 \pm 0.03$ & $0.278 \pm 0.05$ & $5.96 \pm 0.05$ & $0.0543 \pm 0.0006$ & $0.0715 \pm 0.007$ & $0.760 \pm 0.004$ \\
Norm. R:FR & $0.353 \pm 0.04$ & $0.327 \pm 0.03$ & $6.03 \pm 0.12$ & $0.0585 \pm 0.0006$ & $0.0807 \pm 0.008$ & $0.726 \pm 0.004$ \\
$P$ value & $<0.001$ & $<0.001$ & 0.609 & $<0.001$ & $<0.001$ & $<0.001$ \\
\hline
\end{tabular}

Data are the average \pm SE for six plants $(n=6)$. 2010a, 2012, 2015), and suggest that the plants would have improved tolerance to the environmental stress (Itagaki et al., 2016; Latimer and Mitchell, 1988; Shibuya et al., 2010b, 2011) when they are used as transplants.

The DW and leaf area of the seedlings increased exponentially during the treatment. However, the increases of the rates under high-R:FR light were both less than those under normal R:FR (Fig. 2); the differences were significant after 10 and $6 \mathrm{~d}$, respectively. The RGR and RLER under high-R:FR light were $92 \%$ and $85 \%$, respectively, of those under normal R:FR. There was no significant difference in NAR between the treatments (Table 2), indicating that differences in net dry-matter assimilation (i.e., net photosynthesis) did not explain the difference in RGR between the treatments. The LAR of the high-R:FR seedlings was less than that of normal R:FR seedlings, and the proportion $(92 \%)$ was the same as for the RGR (Table 2). This suggests that growth of the high-R:FR seedlings was mainly suppressed by decreased LAR, which is the other component of RGR $(\mathrm{RGR}=\mathrm{NAR} \times$ LAR).

SLA and LWR, which are components of $\mathrm{LAR}(\mathrm{LAR}=\mathrm{SLA} \times \mathrm{LWR})$, under high $-\mathrm{R}: \mathrm{FR}$ light were $89 \%$ and $105 \%$, respectively, of those under normal R:FR light (Table 2). This indicates that the smaller LAR under high-R: FR light, which is the main factor responsible for the smaller RGR, resulted from decreased SLA. In other words, the inhibition of dry matter production under high-R:FR light resulted mainly from suppressed leaf enlargement per unit leaf dry matter but not from a change in the allocation of dry matter between the leaves and other plant parts. This hypothesis has been proposed in previous reports (Fletcher et al., 2005; Li and Kubota, 2009), and was confirmed using the growth analysis results in the present study. The slightly but significantly greater LWR of ably due to decreased biomass allocation to hypocotyl and petiole (Table 1), mitigated the inhibition of dry matter production under high-R:FR light. Casal et al. (1987) suggested that leaf expansion is reduced by FR light due to leaf competition with the stem tissues for photosynthate. The effect of increasing R:FR on leaf expansion and subsequent dry matter production is probably due to the range of R:FR values, which may determine the degree of competition between leaf enlargement and shoot elongation. high-R:FR seedlings (Table 2), which is prob-
In the photosynthesis measurements, $\mathrm{P}_{\mathrm{G}}$ (Fig. 3A) and $\mathrm{P}_{\mathrm{N}}$ (data not shown) per unit leaf area remained relatively constant during the treatment period. There was also no difference in $\mathrm{P}_{\mathrm{G}}$ and $\mathrm{P}_{\mathrm{N}}$ (data not shown) per unit leaf area between the treatments, except $13 \mathrm{~d}$ after seeding (Fig. 3A). This agrees with a previous finding that the R:FR did not affect the photosynthesis per unit leaf area (Heraut-Bron et al., 1999). The reason for the difference in photosynthesis on day 13 is unclear, but the difference was relatively small and may not significantly contribute the total dry matter production. The values of NAR determined from the photosynthesis measurements were $5.49 \pm 0.11 \mathrm{~g} \cdot \mathrm{m}^{-2} \cdot \mathrm{d}^{-1}$ and $5.78 \pm 0.28 \mathrm{~g} \cdot \mathrm{m}^{-2} \cdot \mathrm{d}^{-1}$ under high- and normal-R:FR light, respectively (average \pm $\mathrm{SE}, \mathrm{n}=3$ ); they did not significantly differ $(P=0.400)$. There was no significant interaction effect between the treatment and evaluation method $(P=0.527)$, which means that the NAR results in the growth analysis were validated by the NAR results from the photosynthesis measurements.

The whole-plant $\mathrm{P}_{\mathrm{G}}$ increased exponentially after the treatment began (Fig. 3B). The rate of increase under normal R:FR was greater than that under high-R:FR light, and the difference was significant throughout the treatment period. The whole-plant $\mathrm{P}_{\mathrm{G}}$ was significantly and positively correlated with whole-plant leaf area (Fig. 4). The relationships were equally strong under both light conditions, indicating that the whole-plant $\mathrm{P}_{\mathrm{G}}$ was determined mainly by the leaf area, which defines the plant's light interception capacity. This also supports the result of the growth analysis, in which RGR was determined mainly by LAR in both treatments. Previous studies demonstrated that the photosynthetic capacity per unit leaf area of cucumber could be improved under high-R: FR light (Hogewoning et al., 2010; Shibuya et al., 2010a, 2012, 2015), but photosynthesis did not differ between the treatments in the present study. This is probably due to the relatively low $P P F\left(300 \mu \mathrm{mol} \cdot \mathrm{m}^{-2} \cdot \mathrm{s}^{-1}\right)$, which may have concealed differences in photosynthetic capacity that might have appeared under stronger light. Thus, the disadvantage in dry matter production under the light with high$\mathrm{R}: F R$ seedlings may decrease at higher $P P F$.

In the present study, the seedlings were grown until the first leaf stage to avoid selfshading among the leaves, and were arranged with sufficient space to avoid mutual shading among the neighbors. If the seedlings were grown further or densely, NAR of the normalR:FR seedlings may be decreased earlier than that of the high-R:FR seedlings by self- or mutual-shading, respectively, because of faster leaf enlargement under normal R:FR. In addition, the results would differ among species, because morphological traits including degree of self-shading are often species-specific (Falster and Westoby, 2003).

In conclusion, the present study confirmed that the dry matter production of cucumber seedlings was suppressed under high-R:FR light, mainly due to a reduction of light 


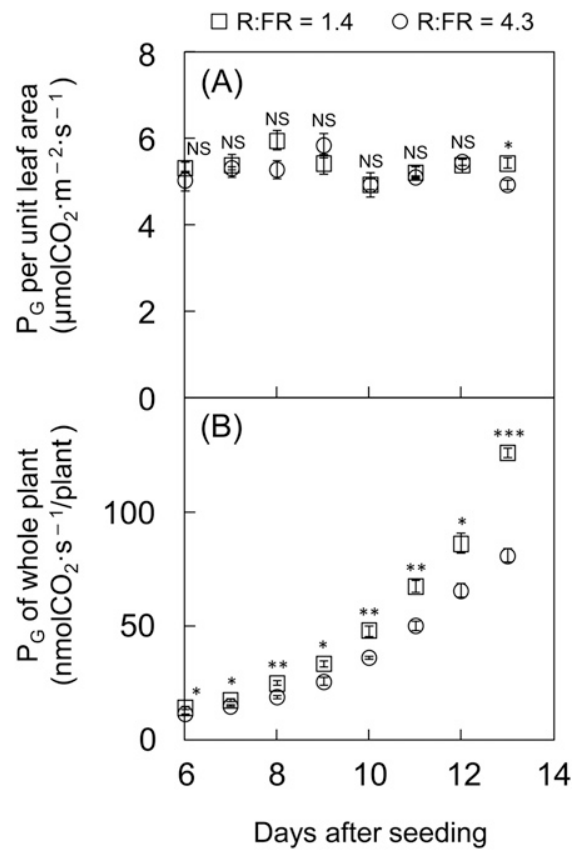

Fig. 3. Time courses of gross photosynthetic rates $\left(\mathrm{P}_{\mathrm{G}}\right)$ per unit leaf area and of whole-plant in cucumber seedlings grown under light with a high red to far-red ratio $(\mathrm{R}: \mathrm{FR}=4.3)$ or natural R:FR (1.4). Data are the average \pm SE of three replicates. NS, no significant difference between the treatment; ${ }^{*} P<0.05 ; * * P<0.01 ; * * * P<$ 0.001 ( $t$ test).

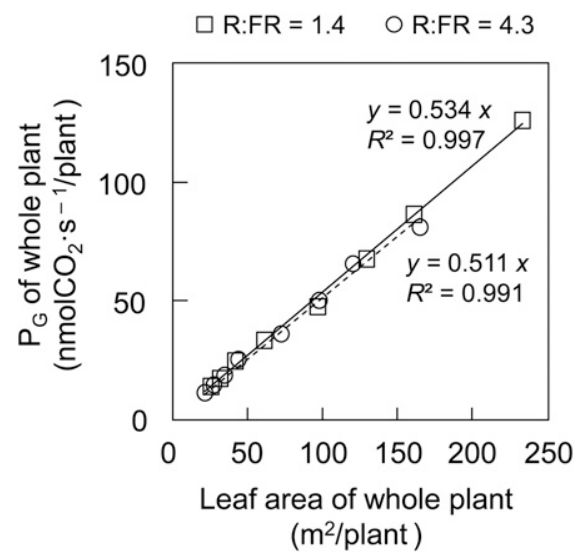

Fig. 4. Relationships between gross photosynthetic rates $\left(\mathrm{P}_{\mathrm{G}}\right)$ of whole-plant and leaf area in cucumber seedlings grown under illumination with a high red to far-red ratio (R:FR $=4.3$ ) or natural $\mathrm{R}: \mathrm{FR}$ (1.4) during the experimental period.

interception that resulted from inhibition of leaf enlargement per unit leaf dry matter. This reduction may have been caused by reduction of cell-wall extensibility, which would also accelerate shoot elongation (Franklin, 2008; Sasidharan et al., 2008). Therefore, the shorter shoots and the faster dry matter accumulation, which are both required in transplant and potplant production, cannot be simultaneously obtained by modifying the R:FR of the light. In controlling R:FR for the plant production, the growers may need to consider which of the advantages is more important.

\section{Literature Cited}

Barreiro, R., J.J. Guiamét, J. Beltrano, and E.R. Montaldi. 1992. Regulation of the photosynthetic capacity of primary bean leaves by the red: Far-red ratio and photosynthetic photon flux density of incident light. Physiol. Plant. 85:97-101.

Casal, J.J., P.J. Aphalo, and R.A. Sánchez. 1987. Phytochrome effects on leaf growth and chlorophyll content in Petunia axilaris. Plant Cell Environ. 10:509-514.

Cerny, T.A., J.E. Faust, D.R. Layne, and N.C. Rajapakse. 2003. Influence of photoselective films and growing season on stem growth and flowering of six plant species. J. Amer. Soc. Hort. Sci. 128:486-491.

Demotes-Mainard, S., T. Péron, A. Corot, J. Bertheloot, J.L. Gourrierec, S. Pelleschi-Travier, L. Crespel, P. Morel, L. Huché-Thélier, R. Boumaza, A. Vian, V. Guérin, N. Leduc, and S. Sakr. 2016. Plant responses to red and far-red lights, applications in horticulture. Environ. Exp. Bot. 121:4-21.

Falster, D.S. and M. Westoby. 2003. Leaf size and angle vary widely across species: What consequences for light interception? New Phytol. 158: 509-525.

Fletcher, J.M., A. Tatsiopoulou, M. Mpezamihigo, J.G. Carew, R.G.C. Henbest, and P. Hadley. 2005. Far-red light filtering by plastic film, greenhouse-cladding materials: Effects on growth and flowering in Petunia and Impatiens. J. Hort. Sci. Biotechnol. 80:303-306.

Franklin, K.A. 2008. Shade avoidance. New Phytol. 179:930-944.

Granier, C. and F. Tardieu. 1998. Spatial and temporal analyses of expansion and cell cycle in sunflower leaves. A common pattern of development for all zones of a leaf and different leaves of a plant. Plant Physiol. 116:991-1001.

Heraut-Bron, V., C. Robin, C. Varlet-Grancher, D. Afif, and A. Guckert. 1999. Light quality (red: Farred ratio): Does it affect photosynthetic activity, net $\mathrm{CO}_{2}$ assimilation, and morphology of young white clover leaves? Can. J. Bot. 77:1425-1431.

Hogewoning, S.W., P. Douwstra, G. Trouwborst, W. Van Ieperen, and J. Harbinson. 2010. An artificial solar spectrum substantially alters plant development compared with usual climate room irradiance spectra. J. Expt. Bot. 61:1267-1276.

Hunt, R., D.R. Causton, B. Shipley, and A.P. Askew. 2002. A modern tool for classical plant growth analysis. Ann. Bot. 90:485-488.

Itagaki, K., T. Shibuya, M. Tojo, R. Endo, and Y. Kitaya. 2016. Early development of powdery mildew on cucumber leaves acclimatized to illumination with different red-to-far-red ratios. HortScience 51:530-536.

Latimer, J.G. and C.A. Mitchell. 1988. Effects of mechanical stress or abscisic acid on growth, water status and leaf abscisic acid content of eggplant seedlings. Sci. Hort. 36:37-46.
Li, Q. and C. Kubota. 2009. Effects of supplemental light quality on growth and phytochemicals of baby leaf lettuce. Environ. Exp. Bot. 67: 59-64.

Li, S., N.C. Rajapakse, R.E. Young, and R. Oi. 2000. Growth responses of chrysanthemum and bell pepper transplants to photoselective plastic films. Sci. Hort. 84:215-225.

Pons, T.L. and Y.E. de Jong-Van Berkel. 2004. Species-specific variation in the importance of the spectral quality gradient in canopies as a signal for photosynthetic resource partitioning. Ann. Bot. 94:725-732.

Radford, P.J. 1967. Growth analysis formulaetheir use and abuse. Crop Sci. 7:171-175.

Rajapakse, N.C. and Y. Shahak. 2007. Light quality manipulation by horticulture industry, p. 290-312. In: G. Whitelam and K. Hallida (eds.). Light and plant development. Blackwell, Oxford, UK.

Rajapakse, N.C., R.E. Young, M.J. McMahon, and R. Oi. 1999. Plant height control by photoselective filters: Current status and future prospects. HortTechnology 9:618-624.

Runkle, E.S. and R.D. Heins. 2002. Stem extension and subsequent flowering of seedlings grown under a film creating a far-red deficient environment. Sci. Hort. 96:257-265.

Sasidharan, R., C.C. Chinnappa, L.A. Voesenek, and R. Pierik. 2008. The regulation of cell wall extensibility during shade avoidance: A study using two contrasting ecotypes of Stellaria longipes. Plant Physiol. 148:1557-1569.

Shibuya, T., R. Endo, N. Hayashi, Y. Kitamura, and Y. Kitaya. 2010a. Potential photosynthetic advantages of cucumber (Cucumis sativus L.) seedlings grown under fluorescent lamps with high red:far-red light. HortScience 45:553-558.

Shibuya, T., R. Endo, N. Hayashi, and Y. Kitaya. 2012. High-light-like photosynthetic responses of Cucumis sativus leaves acclimated to fluorescent illumination with a high red: Far-red ratio: Interaction between light quality and quantity. Photosynthetica 50:623-629.

Shibuya, T., R. Endo, T. Yuba, and Y. Kitaya. 2015. The photosynthetic parameters of cucumber as affected by irradiances with different red: Far-red ratios. Biol. Plant. 59:198-200.

Shibuya, T., K. Itagaki, M. Tojo, R. Endo, and Y. Kitaya. 2011. Fluorescent illumination with high red-to-far-red ratio improves resistance of cucumber seedlings to powdery mildew. HortScience 46:429-431.

Shibuya, T., J. Komuro, N. Hirai, Y. Sakamoto, R. Endo, and Y. Kitaya. 2010b. Preference of sweetpotato whitefly adults to cucumber seedlings grown under two different light sources. HortTchnology 20:873-876.

Smith, H. and G.C. Whitelam. 1997. The shade avoidance syndrome: Multiple responses mediated by multiple phytochromes. Plant Cell Environ. 20:840-844.

Wilson, S.B. and N.C. Rajapakse. 2001. Growth control of lisianthus by photoselective plastic films. HortTechnology 11:581-584.

Yang, Z.Q., Y.X. Li, J.B. Zhang, J. Zhang, J. Zhu, L.L. Gu and B. Zhang. 2014. Effects of the red: far-red light ratio on photosynthetic characteristics of greenhouse cut Chrysanthemum. Hort. Sci. 40:40-43. 